\title{
Glass-Reinforced Plastic Filled by Multiwall Carbon Nanotubes and Their Modified Forms
}

\author{
Yurii Sementsov1,2, Oksana Cherniuk1,2, Galyna Dovbeshko3 ${ }^{3}$, Serhii Zhuravskyi2, \\ Stanislav Makhno², Bo Wang1, Mykola Kartel ${ }^{1,2^{*}}$ \\ ${ }^{1}$ Transportation and Logistics College, Ningbo University of Technology, Ningbo, China \\ ${ }^{2}$ Department of Nanoporous and Nanosized Carbon Materials, Chuiko Institute of Surface Chemistry, NAS of Ukraine, Kyiv, \\ Ukraine \\ ${ }^{3}$ Department of Physics of Biological Systems, Institute of Physics, NAS of Ukraine, Kyiv, Ukraine \\ Email: *nikar@kartel.kiev.ua
}

How to cite this paper: Sementsov, Y., Cherniuk, O., Dovbeshko, G., Zhuravskyi, S., Makhno, S., Wang, B. and Kartel, M. (2019) Glass-Reinforced Plastic Filled by Multiwall Carbon Nanotubes and Their Modified Forms. Journal of Materials Science and Chemical Engineering, 7, 26-35. https://doi.org/10.4236/msce.2019.77004

Received: March 4, 2019

Accepted: July 7, 2019

Published: July 10, 2019

\begin{abstract}
The effect of modifying the surface of multiwall carbon nanotubes (CNT's) by oxygen and nitrogen on the strength characteristics of the fiberglass filled with them was investigated by testing for tension and bending. The method of obtaining nitrogen-containing nanostructures is developed. It was shown that in the epoxide system LR285-LH286 hydrophobic CNT's (outgoing) at introducing into the catalyst polymerization of LH286, increase the strength with respect to unreinforced CNT's by $48 \%$ - 54\%. Oxidized CNT's (200 $\mathrm{A} \cdot \mathrm{h} / \mathrm{kg}$ ) introduced into the resin LR285 increase the strength by $59 \%$. The distribution of the filler particles in size, both in the epoxy resin and in the catalyst, depends on their concentration nonlinear, and correlates with the strength characteristics of the composite.
\end{abstract}

\section{Keywords}

Fiberglass, Multiwall Carbon Nanotubes, Polymer Composite Materials

\section{Introduction}

Due to the outstanding mechanical properties and low density, fiber reinforced polymer composites have been extensively used in high performance applications, such as aerospace, automotive, shipbuilding and sports [1] [2] [3] [4]. Application of nanosized particles as fillers of polymer binder in order to enhance the physico-mechanical characteristics of polymer composites is actively investigated recently [5]-[12]. However, the most common use is the use as a reinforcing element of CNT's as the most effective [13] [14] [15]. The mechanical 
and thermal properties of CNT's are unique and are determined by several factors [16]: high strength of $\mathrm{sp}^{2}$ bonds of C-C; superdense packaging of atoms in the graphene plane; absence or low density of structure defects. Due to this, taking into account the special form factor $(\eta)$ (length-to-diameter ratio) of $10^{3}$, the threshold $\left(\mathrm{F}_{\mathrm{p}}\right) \mathrm{F}_{\mathrm{p}} \sim 1 / \eta$, that is, the concentration at which a continuous grid with CNT's is formed, provided that they are uniformly distributed in the matrix of the polymer may be up to $\approx 0.1 \%$ by weight. CNT's are widely used to obtain new high-strength composite materials of both structural and functional purpose, which are widely used in engineering [1] [2] [3] [4] [17] [18]. As a rule, the addition of any nanosized filler, including CNT's, in the astringent of the composite system increases its physical and mechanical characteristics. The theoretical analysis carried out in various models, for example [19] [20], shows that such a change in properties is due to the characteristics of various phases formed on the interface between the nanofiller and the bulk polymer. Modeling by methods of molecular dynamics [19] demonstrates the formation of an ordered layer of a polymer matrix around CNT's. This layer, known as interphase one, plays a central role in the overall mechanical response of the composite. Due to the poor transfer of the load from the matrix to the CNT's, the effect of gain, attributed to the CNT's, is negligible; consequently, the interphase is considered as the only reason for the enhancement of characteristics in the composite. The purpose of this work was an experimental verification of the influence of the state of the surface of the CNT's on the strength characteristics of the fiberglass, the binding of which was reinforced by CNT's and their forms, which were modified by oxygen and nitrogen.

\section{Methods and Materials}

Multiwall nanotubes (Figure 1) synthesized by the method of catalytic pyrolysis (CCVD), according to [21], conformed to the requirements of the standard TU U 24.1-03291669-009:2009. Complex oxide catalysts with a metal ratio $\left(\mathrm{Al}_{2} \mathrm{FeMo}_{0.21}\right)$ obtained by the aerosol method were used, by decomposing an aqueous mixture of iron citrate and aluminum and molybdenum formates.
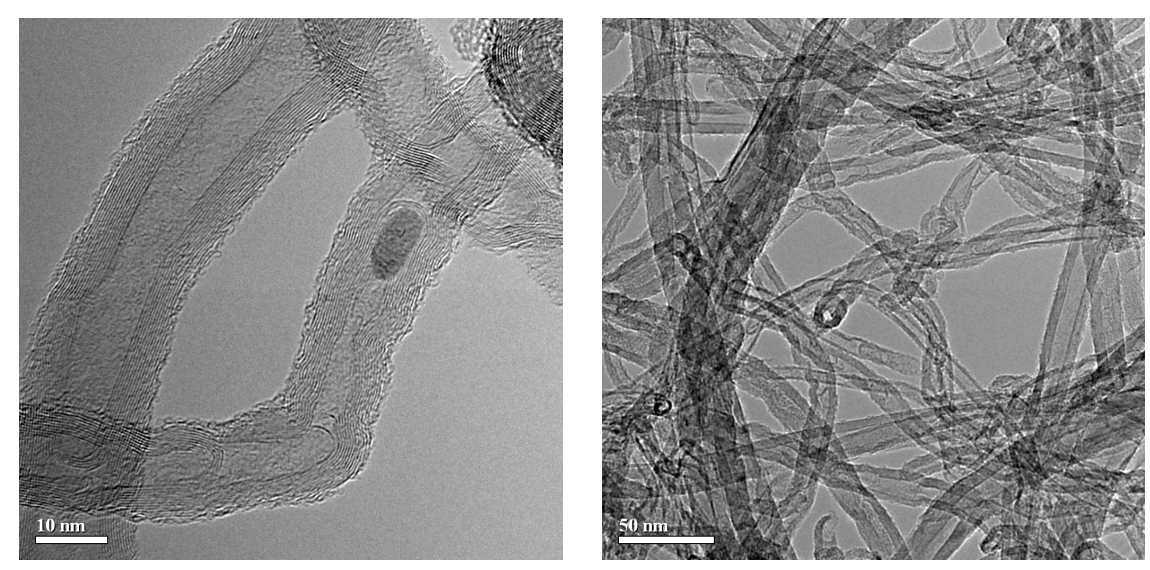

Figure 1. TEM CNT's synthesized from propylene. 
CNT's with $2-40 \mathrm{~nm}$ in the diameter were grown in a $24 \mathrm{dm}^{3}$ reactor with smooth mixing of the catalyst beds due to the rotation of the reactor. The source of carbon was propylene, obtained in the process of dehydration of propanol. Degree of conversion of propylene to carbon under optimal conditions was about $80 \%-97 \%$. To prevent the agglomeration of CNT's in the process of synthesis, a pyrogenic silicon (aerosil) grade A 300 was added to the catalyst. Oxygen modification was carried out by anodic oxidation of CNT's in 94\% sulfuric acid in the reactor according to the scheme [22]. Modification of CNT's by nitrogen was carried out by adding propylene, the main source of carbon, acetonitrile (one nitrogen atom in a molecule) or ethylenediamine (two atoms of nitrogen in a molecule), about $20 \%$ of the volume of propylene. In another embodiment, the carbon source was $100 \%$ acetonitrile or $100 \%$ ethylenediamine. The iron-containing catalyst was used. The prototype of the fiberglass plastics were consisted of two layers of glassfiber with a density of $110 \mathrm{~g} / \mathrm{m}^{2}$ with a core of PVC foam bonded with a binder: an epoxy resin LR285 with a polymerization catalyst LH286 filled with CNT or their modified oxygen or nitrogen forms.

Determination of the specific surface of CNT's was carried out by the method of thermal desorption of argon (GOST 23401-90). The state of the surface of the washed from mineral impurities and dried CNT was investigated by the method of potentiometric micro titration and X-ray photoelectron spectroscopy (XPS), XPS spectrometer "SERIES-800", Kratos Analyticcal using monochromatic $\mathrm{MgK}_{\alpha}$-radiation with energy of $1253.6 \mathrm{eV}$. The structural state of the CNT samples was characterized by the method of Raman scattering (RS). Spectra of RS CNT's was recorded by the Horiba Jobin-Yvon T-64000 spectrometer in combination with the geometry of inverse scattering at room temperature when excited by an argon laser $(\lambda=514.5 \mathrm{~nm}, 1 \mathrm{mV})$. As a standard for calibrating the wavelength, a band of silicon RS was used at $520 \mathrm{~cm}^{-1}$. The introduction of CNT's into the epoxy resin was carried out on a three-hop mixer, and in the polymerization catalyst was processes by ultrasound, as in a less viscous liquid. These methods provided sufficiently homogeneous distribution of CNT's or their modified forms, which was controlled by the laser correlation spectroscopy method of highly diluted solutions in ethanol of epoxy resin and catalyst filled with CNT's. The analysis of particle size and mass was carried out by Malvern Instrument (UK) photoconductivity spectrometer ZetaSizer 3 with correlator 7032 and $25 \mathrm{~mW}$ helium-neon laser LH-111 (wavelength $\lambda=633 \mathrm{~nm}$ ). Mechanical tests of tensile and bending layered composites were conducted on a break-out machine 2167 P 50 with continuous automatic recording of the load-deformation' diagram on a PC.

\section{Experimental Results and Their Discussion}

\subsection{Characterization of CNT and Their Modified Oxygen and Nitrogen Forms}

The oxidation of CNT's results in a slight decrease in the specific surface area 
from $293 \pm 1 \mathrm{~m}^{2} / \mathrm{g}$ for the initial CNT's to $281-285 \mathrm{~m}^{2} / \mathrm{g}$ oxidized by different amounts of electricity. According to the results of potentiometric titration, the values of the SOE of the CNT's of the initial and the CNT's of the oxidized 120 $\mathrm{A} \cdot \mathrm{h} / \mathrm{kg}$ were obtained. They amounted to 1.22 and $1.38 \mathrm{mg}$-equivalent/g, respectively. According to the analysis of the XPS of high resolution spectra, it follows that the outputs of CNT's have $0.75 \%$ at and oxidized $120 \mathrm{~A} \cdot \mathrm{h} / \mathrm{kg}$ at $3.62 \%$ at oxygen. Relative concentrations of oxygen-containing centers are given in Table 1. Thus, the anode treatment of CNT's in $120 \mathrm{~A} \cdot \mathrm{h} / \mathrm{kg}$ significantly (4.8 times) increases the amount of oxygen on the surface of CNT.

The SM spectra and the values of the main parameters of the characteristic bands of the initial CNT's, anode oxidized $120 \mathrm{~A} \cdot \mathrm{h} / \mathrm{kg}$ and modified with nitrogen, are presented in Table 2 and Figure 2. The obtained spectra are typical for multilayer nanotubes (Figure 2).

The G-band (the so-called "graphite" mode of symmetry $\mathrm{E}_{1 \mathrm{~g}}$ at the point $\mathrm{G}$ of the Brillouin zone) is recorded at $1573 \mathrm{~cm}^{-1}$ for the output of CNT's, which

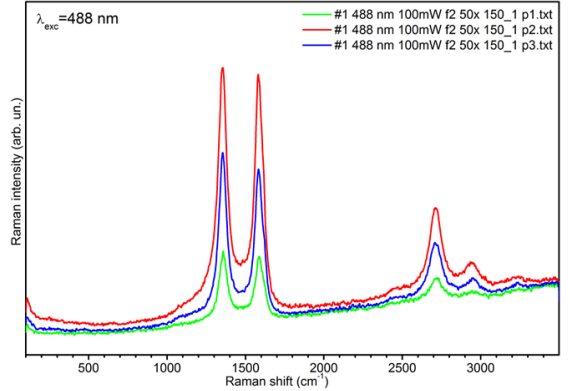

(a)

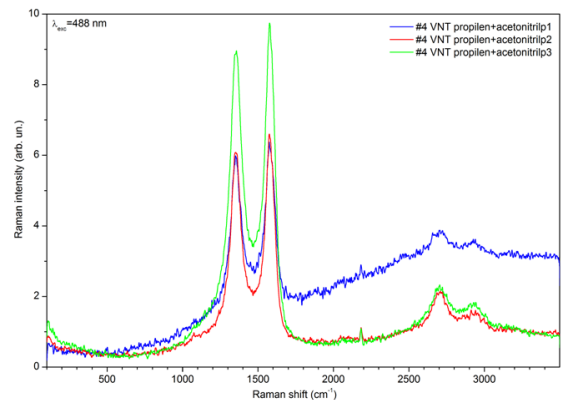

(c)

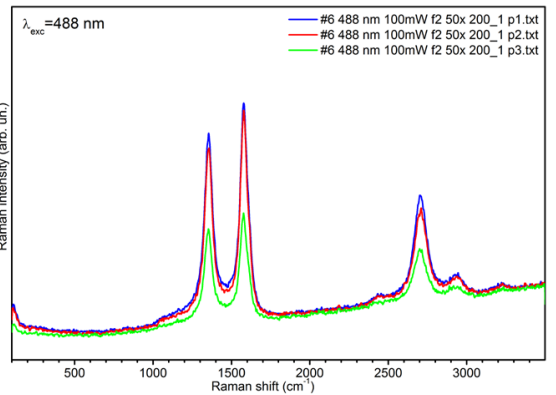

(b)

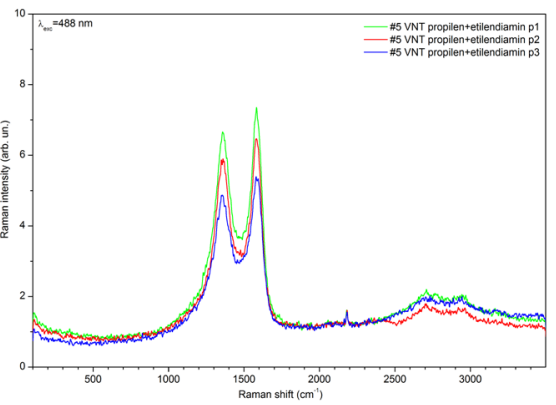

(d)

Figure 2. The SM spectra of CNT's: (a) oxidized, 120 A.h/kg; (b) output CNT's; (c) CNT's obtained with using acetonitrile; (d) CNT's obtained with using ethylenediamine.

Table 1. Relative concentrations of oxygen-containing centers of CNT's and corresponding binding energy.

\begin{tabular}{ccccc}
\hline \multirow{2}{*}{$\begin{array}{c}\text { Samples } \\
\text { of CNT's }\end{array}$} & $\begin{array}{c}\mathrm{E}_{\mathrm{b}}=286.1-1286.3 \\
\mathrm{eV}(\mathrm{C}-\mathrm{OH})\end{array}$ & $\begin{array}{c}\mathrm{E}_{\mathrm{b}}=287.3-287.6 \mathrm{eV} \\
(\mathrm{C}=\mathrm{O})\end{array}$ & $\begin{array}{c}\mathrm{E}_{\mathrm{b}}=288.4-288.9 \mathrm{eV} \\
(\mathrm{C}-\mathrm{OOH})\end{array}$ & $\begin{array}{c}\mathrm{E}_{\mathrm{b}}=290.4-290.8 \mathrm{eV} \\
\left(\mathrm{CO}, \mathrm{CO}_{2}\right)\end{array}$ \\
\hline Outgoing & 49.1 & 17.2 & 17.2 & 16.5 \\
$120 \mathrm{~A} \cdot \mathrm{h} / \mathrm{kg}$ & 53.8 & 19.8 & 13.6 & 12.8 \\
\hline
\end{tabular}


Table 2. The basic parameters of the characteristic bands, which are manifested in the micro-Raman spectra of CNT's of different degrees of oxidation.

\begin{tabular}{ccccccccc}
\hline Samples CNT's & $\mathrm{D}, \mathrm{cm}^{-1}$ & $\mathrm{G}, \mathrm{cm}^{-1}$ & $2 \mathrm{D}, \mathrm{cm}^{-1}$ & $\mathrm{D}_{\mathrm{FWHM}}, \mathrm{cm}^{-1}$ & $\mathrm{G}_{\mathrm{FWHM}}, \mathrm{cm}^{-1}$ & $\mathrm{I}_{\mathrm{D}}$, a.u. & $\mathrm{I}_{\mathrm{G}}$, a.u. & $\mathrm{I}_{\mathrm{D}} / \mathrm{I}_{\mathrm{G}}$ \\
\hline $120 \mathrm{~A} \cdot \mathrm{h} / \mathrm{kg}$ & 1352 & 1583 & 2711 & 55 & 59 & 11.78 & 11.34 & 1.04 \\
outgoing & 1348 & 1573 & 2706 & 51 & 53 & 9.0 & 10.4 & 0.86 \\
acetonitrile & 1352 & 1576 & - & 93 & 84 & 5.55 & 6.0 & 0.92 \\
ethylenediamine & 1360 & 1582 & - & 89 & 90 & 4.96 & 5.5 & 0.90 \\
\hline
\end{tabular}

corresponds to the tangential oscillation of the carbon atoms in the rings of the graphene layer [23]. A so-called $1348 \mathrm{~cm}^{-1}$ band for the outgoing BNT is recorded, which characterizes disordering in graphene multilayer structures, and is not present for a perfect hexagonal lattice graphite [24]. This mode corresponds to the "respiration" fluctuations of the rings of the graphene layer at the point $\mathrm{B}$ of the Brillouin zone. Relative intensity and half-width (FWHM) D and G strips represent the degree of ordering of the graphite-like structure (broadening the band corresponds to a greater degree of disorder). For the output of CNT's, the intensity of the G-mode is slightly higher than the intensity of the D-band, indicating a slight disordering of the structure caused by defects. Due to the low concentration of defects, including the presence of perfect packing of layers in highly oriented graffiti, the D-band is not observed. $120 \mathrm{~A} \cdot \mathrm{h} / \mathrm{kg}$ of electricity leads to a change in the intensity ratio: the intensity of the D-band becomes higher, with the half-width of the G-band becoming larger and shifted towards higher frequencies, that is, the deficiency of CNT's increases. The modification of CNT's by nitrogen obtained from propylene also leads to an increase in defect in the structure of CNT's according to the SM: there is an extension of the G and $\mathrm{D}$ bands and an increase in their frequency. However, the ratio of intensities remains similar to the initial CNT's, i.e. $\mathrm{I}_{\mathrm{D}} / \mathrm{I}_{\mathrm{G}}<1$. Pictures of transmitted electron microscopy of CNT's, which were synthesized from $100 \%$ acetonitrile and $100 \%$ ethylenediamine in the iron-containing catalyst, are presented in Figure 3.

Nanoscale carbon materials with nitrogen inclusion were received using CVD method in the followings works: by decomposition of ethylene-ammonia mixtures on metal catalysts [25], xylol/pyridine and ferrocene pyrolysis [26] using modified precursor feed, acetonitrile [27], pyridine or N, N-dimethylformamide with catalyst Fe-, Co- or Ni in the temperature interval 823 - $1123 \mathrm{~K}$, also observed bamboo-like structures. Moreover, a uniform distribution of nitrogen and the formation of ordered defects were recorded in N-CNT's [25]. In accordance with the performed structural modeling, the ordered defects contain four carbon vacancies and pyridine-like nitrogen. On the contrary, it has been found that N-CNF's (carbon fibers) have an uneven distribution of nitrogen; their structural defects are disordered and also contain pyridine-like nitrogen. It is noted in [26] that the system creates a nitrogen concentration gradient, which modifies the CNT's from the hollow cylinder to a bamboo structure, which contains a number of compartments whose lengths gradually decrease with increasing 


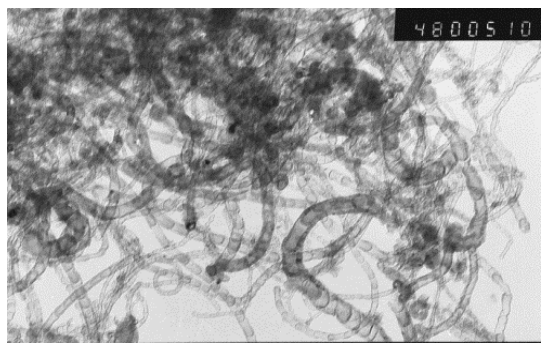

(a)

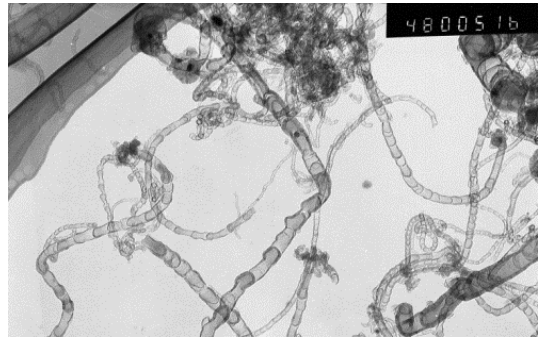

(b)

Figure 3. Transmission electron microscopy pictures of the product obtained from: (a) $100 \%$ acetonitrile; (b) $100 \%$ of ethylenediamine.

nitrogen concentration. The physical and chemical properties of the resulting $\mathrm{N}-\mathrm{CNT}$ 's, such as the ratio of $\mathrm{C} / \mathrm{N}$ or the type of nitrogen, are related to the synthesis parameters. It was found [27] that the $\mathrm{C} / \mathrm{N}$ ratio increases with temperature, which may be due to the thermodynamic stability of metal carbides and metal nitrides. Also, the kind of nitrogen present in the layer of graphene varied with increasing temperature from predominantly pyridine-to quaternary nitrogen. N-CNT's produced from the Fe catalyst showed bamboo morphology regardless of the source $\mathrm{C} / \mathrm{N}$ or growth temperature, whereas direct tubes were obtained with a Co or Ni catalyst. The authors assume that this difference in morphology can be explained by the thermodynamic stability of various metal carbides, which leads to "pulsating" growth in the case of Fe in contrast to more continuous growth in the case of Co or $\mathrm{Ni}$.

\subsection{Obtaining of Layered Composites and Study of Their Mechanical Characteristics}

According to the results of LCS analysis of solutions of epoxy resins and polymerization catalyst with the content of CNT's of different concentrations, it was found that on average: in the epoxy resin, the majority of particles (over 40\%) have a size within the range of $30-100 \mathrm{~nm}$; also particles (up to $35 \%$ ) in the size of $130-1200 \mathrm{~nm}$ and large particles (up to 5\%) in the size $3.5-7.0$ microns are observed; in the case of polymerization catalyst, 2 peaks were found in sizes from 300 to $1200 \mathrm{~nm}(18 \%)$ and from 4 to 7.9 microns (32\%), but by the amount most of the particles (45\%) corresponded to the size of $20 \mathrm{~nm}$. The distribution of the particle size in both the epoxy resin and catalyst depends on the concentration of the filler, and it is nonlinear and correlates with the strength characteristics. Model specimens of three-layer composites with a core of PVC foam were obtained by vacuum pressing. The influence of CNT's concentration and the method of administration (separately in the epoxy resin and separately in the polymerization catalyst) on the tensile strength and bending strength were investigated. Figure 4 shows the dependences of increasing tensile strength and bending strength on the CNT's concentration relative to the sample of the unloaded CNT's. As can be seen from the dependencies in Figure 4, at introducing CNT into the polymerization catalyst, increase of the strength are observed at lower 


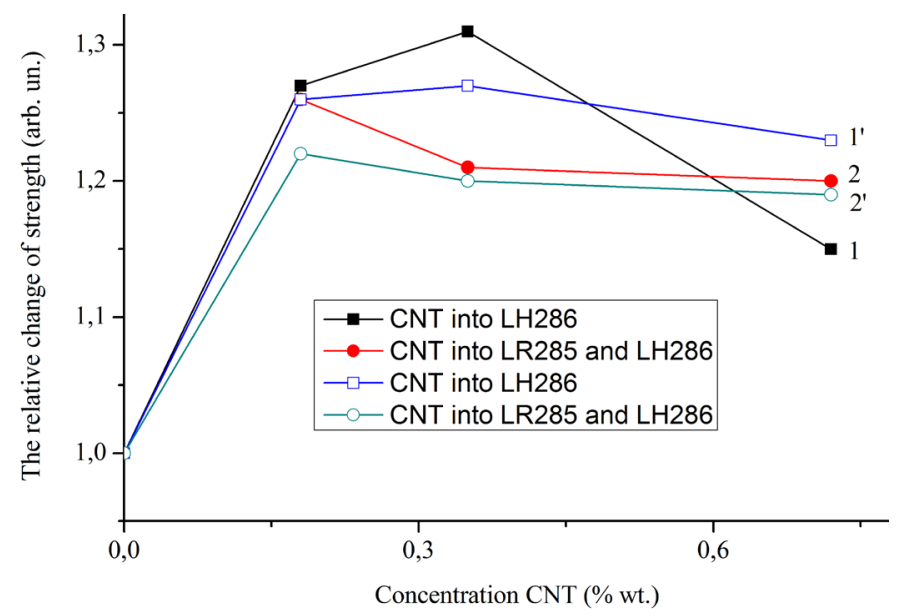

Figure 4. The relative increase of the strength of the layered PCM. CNT's are introduced: into LH286, 1) tensile, 1') bending; into LR285; 2) tensile, 2') bending.

concentrations of CNT's (an increase of $25 \%-30 \%$ in the range of $0.2 \%-0.4 \%$ wt of CNT's). This indicates that the introduction of CNT's into a polymerization catalyst (less viscous fluid) and ultrasound treatment provides a more effective, i.e. more homogeneous distribution of CNT's in an epoxy binder. As one can see in Table 3, the bending strength of the model specimens, which consisted of two layers of glass fiber with a density of $110 \mathrm{~g} / \mathrm{m}^{2}$, with a core of PVC foam, an epoxy binder LR285, a polymerization catalyst of LH286 without CNT's and filled with different types of CNT's and modified with oxygen and nitrogen with a concentration of $0.3 \%$ wt. in relation to the hard binder.

CNT's and their modified forms were introduced both in the LR285 resin and in the LH286 hardener.

As one can notice from the data in Table 3, technological variants for the introduction CNT's in the glassfiber material significantly affect its strength. So, if you introduce hydrophobic CNT's (Samples 2 - 4) into a catalyst for polymerization of LH 286, then the strength with respect to non-reinforced CNT's samples increases by $48 \%-54 \%$. In this case, if they are injected into an epoxy resin, then the increase in strength is only $11 \%-13 \%$. But the introduction of oxidized CNT's shows the opposite effect. Oxidized CNT's (200 A.h $/ \mathrm{kg}$ ) added to the resin increases strength by as much as $59 \%$. Their introduction into the hardener gives the lower effect of increasing the strength, as the degree of oxidation is higher (Samples 8, 9 in Table 3). Nitrogen-containing nanostructures also give the effect of increasing the strength significantly less, but both when introduced into the resin and hardener.

To explain this effect as a hypothesis, one can propose the following. Amine hardener (such as LH286) in interaction with CNT's acts as a surfactant. When interacting with the initial CNT's, it is guided by the hydrocarbon part to the tube, and the amino groups are externally. The resulting superficial layer prevents reverse agglomeration of CNT's after dispersion. Since amino groups in particular are reacted with resin epoxies, the ends of the polymer chains during 
Table 3. Dependence of the bending strength of the model on the samples on the origin of CNT's and the method of their introduction in the binding.

\begin{tabular}{|c|c|c|c|c|}
\hline \multicolumn{5}{|c|}{$\begin{array}{c}\text { Homogeneous distribution of CNT's and their modified forms } \\
0.3 \% \text { wt. in relation to the mass of the approved resin }\end{array}$} \\
\hline \multirow{2}{*}{ Type of filler } & \multicolumn{2}{|c|}{$\begin{array}{l}\text { Ultrasound treatment in a } \\
\text { polymerization catalyst } \\
\text { (hardener LH286) }\end{array}$} & \multicolumn{2}{|c|}{$\begin{array}{l}\text { Mixing on three roller mills } \\
\text { in epoxy resin LR285 }\end{array}$} \\
\hline & $\begin{array}{l}\text { Bending } \\
\text { strength, } \\
\mathrm{MPa}\end{array}$ & $\begin{array}{l}\text { Change in strength } \\
\text { to non-reinforced } \\
\text { CNT's samples }\end{array}$ & $\begin{array}{l}\text { Bending } \\
\text { strength, } \\
\mathrm{MPa}\end{array}$ & $\begin{array}{l}\text { Change in strength } \\
\text { to non-reinforced } \\
\text { CNT's samples }\end{array}$ \\
\hline Without CNT's & 26.96 & - & 26.96 & \\
\hline Outgoing CNT's & 41.51 & 1.54 & 30.57 & 1.13 \\
\hline CNT's on a pyrogenic catalyst & 39.90 & 1.48 & 29.96 & 1.11 \\
\hline CNT"s "short" & 40.43 & 1.50 & - & - \\
\hline $\mathrm{N}$-consistent CNT's & 33.58 & 1.25 & 29.59 & 1.10 \\
\hline CNT's, China & 26.92 & 1.00 & 31.85 & 1.18 \\
\hline Oxidized $120 \mathrm{~A} \cdot \mathrm{h} / \mathrm{kg}$ & 33.36 & 1.24 & - & - \\
\hline Oxidized $200 \mathrm{~A} \cdot \mathrm{h} / \mathrm{kg}$ & 27.36 & 1.01 & 42.88 & 1.59 \\
\hline
\end{tabular}

curing should be "attached" to CNT's (the interaction of the polymer matrix with the CNT's surface increases). That is why Nitrogen-containing CNT's behave a little worse, because they have a more charged surface. Oxidized tubes at the expense of acidic groups on the surface of the opposite turn the molecules of the hardener to amino groups to the surface of the CNT's and the hydrocarbon residue outside, i.e., there is no charged layer to prevent agglomeration. Also, due to such an orientation of the amino group, the corrector molecules are adsorbed on the surface of the CNT's if they are screened by their own hydrocarbon residues from epoxy resin groups during curing (which leads to a weakening of the bond of CNT's with a polymer matrix). In the case of dispersion of oxidized CNT's in a resin, the most oxygen-containing groups on the surface of the CNT's, due to their polarity, prevent reverse agglomeration after dispersion.

\section{Conclusion}

It was shown experimentally that the multilayer CNT's which were synthesized by CCVD method at introducing into the epoxy system of LR285-LH286, increase the strength of a model laminated fiberglass with a porous core with respect to stretching and bending by $25 \%-35 \%$ at low concentrations of CNT's (up to $0.4 \% \mathrm{wt}$ ). The effect increases with the introduction of CNT's into a less viscous fluid, namely the polymerization catalyst LH286. Modifying the surface of CNT's with oxygen and nitrogen changes their interaction with the epoxy matrix. Hydrophobic CNT's (output) at introducing into the catalyst polymerization of LH286, increase strength with respect to unreinforced CNT's by $48 \%$ $54 \%$. The oxidized CNT's (200 A.h $/ \mathrm{kg}$ ) introduced into the resin increases the strength by $59 \%$. 


\section{Conflicts of Interest}

The authors declare no conflicts of interest regarding the publication of this paper.

\section{References}

[1] Kalgin, A.V., Kalinin, Yu.E., Kudrin, A.M., Maluchenkov, A.V., Panin, Yu.V. and Sytnikov, A.V. (2011) Prospects for the Development of the Production of Aircraft Parts Made of Composite Materials. VSTU Bulletin, 112, 147-149. (In Russian)

[2] Savin, S.P. (2012) The Use of Modern Polymer Composite Materials in the Construction of a Glider Aircraft of the MS-21 Family. News of the Samara Scientific Center of the Russian Academy of Sciences, 4, 1-4. (In Russian)

[3] Zazimko, V. (2017) The Use of Composite Materials as a Driver of the Branches of the Military Industrial Complex. New Defense Order. Strategies, 2, 56-58. (In Russian)

[4] Cowan, T., Acar, E. and Francolin, C. (2006) Analysis of Causes and Statistics of Commercial Jet Plane Accidents between 1983 and 2003. Mechanical and Aerospace Engineering Department University of Florida, ST1, 1-15.

[5] Tian, Y., Zhang, H. and Zhang, Z. (2017) Influence of Nanoparticles on the Interfacial Properties of Fiber-Reinforced-Epoxy Composites. Composites: Part A, 98, 1-8. https://doi.org/10.1016/j.compositesa.2017.03.007

[6] Scarselli, G., Corcione, C., Nicassio, F. and Maffezzoli, A. (2017) Adhesive Joints with Improved Mechanical Properties for Aerospace Applications. International Journal of Adhesion and Adhesives, 75, 174-180. https://doi.org/10.1016/j.ijadhadh.2017.03.012

[7] Lin, F., Yang, C., Zeng, Q.H. and Xiang, Y. (2018) Morphological and Mechanical Properties of Graphene-Reinforced PMMA Nanocomposites Using a Multiscale Analysis. Computational Materials Science, 150, 107-120. https://doi.org/10.1016/j.commatsci.2018.03.048

[8] Liang, M. and Wong, K.L. (2017) Study of Mechanical and Thermal Performances of Epoxy Resin Filled with Micro Particles and Nanoparticles. Energy Procedia, 110, 156-161. https://doi.org/10.1016/j.egypro.2017.03.121

[9] Irez, A.B., Bayraktar, E. and Miskioglu, I. (2017) Design and Mechanical-Physical Properties of Epoxy-Rubber Based Composites Reinforced with Nanoparticles. Procedia Engineering, 184, 486-496. https://doi.org/10.1016/j.proeng.2017.04.119

[10] Eesaee, M. and Shojaei, A. (2014) Effect of Nanoclays on the Mechanical Properties and Durability of Novolac Phenolic Resin/Woven Glass Fiber Composite at Various Chemical Environments. Composites. Part A, 63, 149-158. https://doi.org/10.1016/j.compositesa.2014.04.008

[11] Anbusagar, N.R.R., Palanikumar, K. and Giridharan, P.K. (2015) Study of Sandwich Effect on Nanoclay Modified Polyester Resin GFR Face Sheet Laminates. Composite Structures, 125, 336-342. https://doi.org/10.1016/j.compstruct.2015.02.016

[12] Boumaza, M., Khan, R. and Zahrani, S., (2016) An Experimental Investigation of the Effects of Nanoparticles on the Mechanical Properties of Epoxy Coating. Thin Solid Films, 620, 160-164. https://doi.org/10.1016/j.tsf.2016.09.035

[13] Kaseem, M., Hamad, K. and Ko, Y.G. (2016) Fabrication and Materials Properties of Polystyrene/Carbon Nanotube (PS/CNT) Composites: A Review. European Polymer Journal, 79, 36-62. https://doi.org/10.1016/j.eurpolymj.2016.04.011

[14] Banks-Sills, L., Shiber, D.G., Fourman, V., Eliasi, R. and Shlayer, A. (2016) Experi- 
mental Determination of Mechanical Properties of PMMA Reinforced with Functionalized CNTs. Composites Part B: Engineering, 95, 335-345.

https://doi.org/10.1016/j.compositesb.2016.04.015

[15] Nam, T.H., Goto, K., Yamaguchi, Y., Premalal, E.V.A., Shimamura, Y., Inoue, Y., et al. (2015) Effects of CNT Diameter on Mechanical Properties of Aligned CNT Sheets and Composites. Composites Part A: Applied Science and Manufacturing, 76, 289-298. https://doi.org/10.1016/j.compositesa.2015.06.009

[16] Rakov, E.G. (2006) Nanotubes and Fullerenes. University Book, Moscow. (In Russian)

[17] Kablov, E.N., Kondrashov, S.V. and Yurkov, G.Yu. (2013) Prospects for the Use of Carbon-Containing Nanoparticles in Binders for Polymer Composites. Nanotechnologies in Russia, 8, 163-185.

https://link.springer.com/article/10.1134/S1995078013020080 https://doi.org/10.1134/S1995078013020080

[18] Lin, S., Anwer, M.A.S., Zhou, Y., Sinha, A., Carson, L. and Naguib, H.E. (2018) Evaluation of the Thermal, Mechanical and Dynamic Mechanical Characteristics of Modified Graphite Nanoplatelets and Graphene Oxide High-Density Polyethylene Composites. Composites Part B: Engineering, 132, 61-68.

https://doi.org/10.1016/j.compositesb.2017.08.010

[19] Malagù, M., Goudarzi, M., Lyulin, A., Benvenuti, E. and Simone, A. (2017) Diameter-Dependent Elastic Properties of Carbon Nanotube-Polymer Composites: Emergence of Size Effects from Atomistic-Scale Simulations. Composites Part B: Engineering, 131, 260-281. https://doi.org/10.1016/j.compositesb.2017.07.029

[20] Cen-Puc, M., Oliva-Avilés, A.I. and Avilés, F. (2018) Thermoresistive Mechanisms of Carbon Nanotube/Polymer Composites. Physica E, 95, 41-50. https://doi.org/10.1016/j.physe.2017.09.001

[21] Melezhyk, A.V., Sementsov, Yu.I. and Yanchenko, V.V. (2005) Synthesis of Thin Carbon Nanotubes on Co-Precipitated Metaloxide Catalysts. Russian Journal of Applied Chemistry, 78, 938-944. (In Russian)

https://elibrary.ru/item.asp?id=9148431

[22] Sementsov, Yu.I., Revo, S.L. and Ivanenko, K.O. (2016) Thermo-Expanded Graphite. Interservis, Kyiv. (In Ukrainian)

[23] Ferrari, A.C. (2006) Raman Spectrum of Graphene and Graphene Layers. Phys. Rev. Lett., 97, Article ID: 187401. https://doi.org/10.1103/PhysRevLett.97.187401

[24] Whitby, R.L.D., Gun’ko, V.M., Korobeinyk, A., Busquets, R., Cundy, A.B., László, K., et al. (2012) Driving Forces of Conformational Changes in Single-Layer Graphene Oxide. ACS Nano, 6, 3967-3973. https://doi.org/10.1021/nn3002278

[25] Podyacheva, O.Yu., Cherepanova, S.V., Romanenko, A.I., Kibis, L.S., Svintsitskiy, D.A. and Boronin, A.I. (2017) Nitrogen Doped Carbon Nanotubesand Nanofibers: Composition, Structure, Electrical Conductivity and Capacity Properties. Carbon, 122, 475-483. https://doi.org/10.1016/j.carbon.2017.06.094

[26] Xu, E., Wei, J., Wang, K., Li, Z., Gui, X., Jia, Y., et al. (2010) Doped Carbon Nanotube Array with a Gradient of Nitrogen Concentration. Carbon, 48, 3097-3102. https://doi.org/10.1016/j.carbon.2010.04.046

[27] Dommele, S., Romero-Izquirdo, A., Brydson, R., Jong, K.P. and Bitter, J.H. (2008) Tuning Nitrogen Functionalities in Catalytically Grown Nitrogen-Containing Carbon Nanotubes. Carbon, 46, 138-148. https://doi.org/10.1016/j.carbon.2007.10.034 